\title{
Voluntary exercise can strengthen the circadian system in aged mice
}

\author{
T. L. Leise • M. E. Harrington • P. C. Molyneux • \\ I. Song • H. Queenan • E. Zimmerman • G. S. Lall • \\ S. M. Biello
}

Received: 2 July 2012 / Accepted: 5 December 2012 / Published online: 23 January 2013

(C) The Author(s) 2013. This article is published with open access at Springerlink.com

\begin{abstract}
Consistent daily rhythms are important to healthy aging according to studies linking disrupted circadian rhythms with negative health impacts. We studied the effects of age and exercise on baseline circadian rhythms and on the circadian system's ability to respond to the perturbation induced by an $8 \mathrm{~h}$ advance of the light:dark (LD) cycle as a test of the system's robustness. Mice (male, $\mathrm{mPer} 2^{\text {luc }} / \mathrm{C} 57 \mathrm{BL} / 6$ ) were studied at one of two ages: 3.5 months $(n=39)$ and $>18$ months $(n=72)$. We examined activity records of these mice under entrained and shifted conditions as well as mPER2::LUC measures ex vivo to assess circadian
\end{abstract}

Electronic supplementary material The online version of this article (doi:10.1007/s11357-012-9502-y) contains

supplementary material, which is available to authorized users.

M. E. Harrington $(\bowtie) \cdot$ P. C. Molyneux $\cdot$ I. Song $\cdot$

H. Queenan • E. Zimmerman

Neuroscience Program, Smith College,

Northampton, MA 01063, USA

e-mail: mharring@smith.edu

T. L. Leise

Mathematics Department, Amherst College,

Amherst, MA 01002, USA

G. S. Lall

Medway School of Pharmacy, University of Kent,

Central Avenue, Chatham,

Kent ME4 4TB, UK

S. M. Biello

School of Psychology, University of Glasgow,

Glasgow G12 8QB Scotland, UK function in the suprachiasmatic nuclei (SCN) and important target organs. Age was associated with reduced running wheel use, fragmentation of activity, and slowed resetting in both behavioral and molecular measures. Furthermore, we observed that for aged mice, the presence of a running wheel altered the amplitude of the spontaneous firing rate rhythm in the SCN in vitro. Following a shift of the LD cycle, both young and aged mice showed a change in rhythmicity properties of the mPER2::LUC oscillation of the SCN in vitro, and aged mice exhibited longer lasting internal desynchrony. Access to a running wheel alleviated some age-related changes in the circadian system. In an additional experiment, we replicated the effect of the running wheel, comparing behavioral and in vitro results from aged mice housed with or without a running wheel ( $>21$ months, $n=8$ per group, all examined 4 days after the shift). The impact of voluntary exercise on circadian rhythm properties in an aged animal is a novel finding and has implications for the health of older people living with environmentally induced circadian disruption.

Keywords Circadian - Exercise - Wheel .

Suprachiasmatic nucleus · Thymus · Esophagus · Spleen

\section{Introduction}

Aging can impact circadian (daily) rhythms leading to impaired sleep and activity cycles. Older adults show 
reduced amplitude of rhythms (Münch et al. 2005), manifested most obviously as disrupted sleep. Healthy older adults can exhibit dysfunctions of sleep and wake, including difficulty initiating sleep, frequent nighttime awakenings, and early morning wake times (Buysse et al. 2005). These observed alterations in the daily rhythm of sleep and wake are attributable to changes in the interplay between homeostatic sleep mechanisms and circadian clock parameters (Dijk et al. 2000). In addition, aging of the clock affects mood and memory and contributes to age-associated cognitive decline (Nebes et al. 2009; Grandner et al. 2012). Decreased locomotor activity rhythm amplitude is associated with increased risk of mortality (Tranah et al. 2010), and sleep loss in the elderly has been linked to increased incidence of falls, accidents, poor health status, and mortality (Ancoli-Israel and Alessi 2005; Foley et al. 1995; Foley et al. 1999). These findings suggest a possible link between deficits in circadian rhythmicity and less successful aging, although the data are corelational so a causal relationship cannot be inferred in many of these human studies.

Rodents also show significant changes in circadian function with age, including reduced amplitude of output rhythms, providing an excellent model through which to study the basic mechanisms of age-related changes in the circadian clock. Earlier work found changes in a number of circadian parameters in the activity of C57BL/6 mice with senescence in vivo (Valentinuzzi et al. 1997). The central circadian pacemaker in mammals is located within the suprachiasmatic nuclei (SCN) in the hypothalamus (Rusak and Zucker 1979). The network of neurons in the SCN generates an approximately 24 -h oscillation via transcriptional-translational feedback loops of clock gene expression and also exhibits daily patterns in neuronal firing rate. The amplitude and phase synchrony of electrical activity of SCN neurons are affected by age in rats and mice (Farajnia et al. 2012; Nakamura et al. 2011; Satinoff et al. 1993). While aspects of input pathways or SCN cell response are impaired in aged animals (Benloucif et al. 1997; Biello 2009; Zhang et al. 1996; 1998), some specific deficits seen in circadian behavior of aged mice might be attributable to deficits not within the clock mechanism but in communication from the molecular clock to output targets. This is supported by studies showing unaltered rhythms in core clock genes per 1 and per 2 in the SCN of aged animals (Kolker et al. 2003), yet with dramatic changes seen in neuronal firing rate output rhythms (Nakamura et al. 2011; Satinoff et al. 1993) as well as in behavioral rhythms (Valentinuzzi et al. 1997).

Communication from the clock to output targets is necessary to maintain the internal phase relationships of the peripheral and central circadian clocks that comprise the circadian system. Several prior studies using rats with a bioluminescent reporter for the clock gene per1 (Davidson et al. 2008; Yamazaki et al. 2002) indicate that, in vitro, some peripheral tissues show altered phase with the light:dark (LD) cycle in aged rats and some peripheral tissues seem to have markedly damped rhythmicity. If advancing age negatively affects communication from central to peripheral clocks, we would expect a deficit in the response to a shift in the entraining light cycle. The current understanding of "jet lag" following a shift of the entraining cycle is that it arises from a failure of the SCN clock to rapidly transmit the shifted clock signal to peripheral tissues (Yamazaki et al. 2000), with coincident disruption among cell populations within the SCN (Davidson et al. 2009; Nagano et al. 2003; Nakamura et al. 2005). Circadian clocks in extra-SCN brain regions as well as those outside the central nervous system shift at varied rates (Kiessling et al. 2010; Yamazaki et al. 2000), leading to a state of internal temporal desynchrony that may impair cognition and health (Castanon-Cervantes et al. 2010; Lee et al. 2010; Martino et al. 2008; Karatsoreos et al. 2011; Cho 2001). Central and peripheral oscillators respond to a shift of the light cycle differently in young and aged mice, providing further evidence that aging alters circadian function (Sellix at al. 2012). To test if age impacts circadian clock output, we can track resynchronization to a shifted LD cycle using both behavioral measures in vivo and bioluminescent mPER2::LUC ex vivo (Yoo et al. 2004) to assess phase and rhythmicity of SCN and peripheral oscillators. These measures provide a window into the dynamics of resynchronization of the entire circadian system and assessment of any age-related deficits.

We hypothesized that aged mice will demonstrate deficits in resynchronization following an $8 \mathrm{~h}$ advance in the LD cycle, either in total time required for complete circadian system resynchronization and/or in degree of internal desynchrony during the time period of phase shift dynamics. To test this hypothesis, we monitored motion and wheel-running activity of $\mathrm{mPer} 2{ }^{\text {luc }}$ mice and recorded PER2::LUC bioluminescence rhythms in the 
SCN and three important target organs. We further hypothesized that there would be no deficits in cycling of SCN mPER2::LUC in aged control unshifted mice, given prior research that has not indicated appreciable deficits in period gene cycling in aged animals (Asai et al. 2001; Kolker et al. 2003; Nakamura et al. 2011; Yamazaki et al. 2002). A prior study suggested that age affected the rate of resynchronization of peripheral targets but did not alter SCN resetting dynamics in Perl-luc rats (Davidson et al. 2008), supporting a hypothesis that age-related deficits will be restricted to target tissues but will not be observed in the SCN.

To explore ways to counteract age-associated changes, we tested if access to a running wheel could have a beneficial effect on the temporal organization of the circadian system in mice under control conditions as well as in response to the LD shift. Exercise can lessen the negative impact of age on learning and memory, neurogenesis, and motor behavior in mice (Marlatt et al. 2012). Running wheels can alter key properties of rodent circadian rhythms such as period and rate of resynchronization (Castillo et al. 2011; Harrington et al. 2007) and exercise can also benefit consolidation of sleep and activity rhythms in people (King et al. 1997; Passos et al. 2011; Reid et al. 2010). Here, we determined if naturally increased activity by voluntary use of a running wheel altered effects of age on circadian system dynamics using electrophysiological, molecular, and behavioral measures.

\section{Methods}

\section{Electrophysiological experiments}

Fourteen male C57BL/6 mice (University of Glasgow) were housed under an LD schedule of 12:12 h. While they had all experienced a wheel in their cage at various times between 4 and 6 months of age, for the 9-11 months prior to the beginning of this experiment, these mice had no wheel exposure. At the start of this experiment, seven mice were placed in cages containing running wheels, while the other seven remained in their home cage with no wheel.

Mice (18-20 months) were administered an overdose of halothane anesthesia and decapitated during the phases when this manipulation does not induce phase shifts (Gillette 1986), in most cases, between Zeitgeber Time (ZT) 2 and 5. Hypothalamic slices
$(500 \mu \mathrm{m})$ containing the $\mathrm{SCN}$ were placed in a gasfluid interface slice chamber (Medical Systems BSC with Haas top), continuously bathed $(1 \mathrm{ml} / \mathrm{min})$ in artificial cerebrospinal fluid (ACSF) containing $125.2 \mathrm{mM} \mathrm{NaCl}, 3.8 \mathrm{mM} \mathrm{KCl}, 1.2 \mathrm{mM} \mathrm{KH}_{2} \mathrm{PO}_{4}$, $1.8 \mathrm{mM} \mathrm{CaCl}_{2}, 1 \mathrm{mM} \mathrm{MgSO} 4,24.8 \mathrm{mM} \mathrm{NaHCO}_{3}$, and $10 \mathrm{mM}$ glucose. ACSF (pH 7.4) was maintained at $34.5{ }^{\circ} \mathrm{C}$. Warm, humidified $95 \%$ oxygen:5 \% carbon dioxide was continuously provided.

Extracellular single unit activity of SCN cells was detected with glass micropipette electrodes filled with ACSF, advanced through the slice using a hydraulic microdrive. The electrode was placed into regions of the SCN at random, alternating between the left and right SCN. The signal was fed into an amplifier for further amplification and filtering and was continuously monitored by an oscilloscope and audio monitor. Firing rate and interspike interval data were analyzed using Spike (Cambridge Electronic Design Ltd., Cambridge, UK) data acquisition software and a customized program for calculation of descriptive statistics. The average spontaneous firing rate and the ZT for each single unit encountered was recorded for 4$5 \mathrm{~min}$ by an experimenter blind to the condition.

Recordings were typically performed for $8-12 \mathrm{~h}$ during ZT $0-12$ of the second $24 \mathrm{~h}$ in vitro. One slice from each old mouse $(n=7)$ with a wheel and each old mouse $(n=7)$ without a wheel were monitored continuously for $32 \mathrm{~h}$ from ZT 0 of the first day in vitro.

\section{Behavioral and bioluminescence experiments}

Mice (male, mPer $2^{\text {luc/+ }}$ and mPer $2^{\text {luc/luc }}$ on a C57BL/6 background; total $n=120$ ) were bred in-house (Smith College) from founders from Dr. J. Takahashi (University of Texas Southwestern). In the first experiment, mice were studied at one of two ages: $105 \pm$ 3 days $(n=39)$ or $579 \pm 5$ days $(n=72)$. Mice were individually housed and behavioral activity rhythms were measured by monitoring of a running wheel installed in each cage as well as by a motion sensor positioned on the cage lid, connected to a computer running ClockLab software (Actimetrics Inc., Wilmette, IL, USA). Following entrainment to a LD cycle 12:12 (light intensity: $350-400 \mathrm{~lx}$ ), the LD cycle was phase advanced by $8 \mathrm{~h}$ via a short night. At various times throughout the experiment, mice were euthanized for recording of tissue rhythms in vitro. The mouse was taken from its cage within an hour 
of ZT 2 of the original entraining cycle and ZT 10 of the phase advanced cycle (ZT 12 is defined as the time of lights off), based on prior research showing that dissection in this time window does not reset phase (Davidson et al. 2009). Mice were euthanized either prior to the LD shift or on Days 2, 4, and 9, following the LD shift. Control unshifted mice were euthanized between ZT 2 and 10 with the exception of two subgroups of aged mice housed with running wheels that were euthanized either ZT2-3 or between ZT 10 and 11 to check for time of dissection effects in the aged mice. Mice were overdosed with isoflurane anesthesia and the brain was quickly removed and sections $(300 \mu \mathrm{m})$ containing the SCN were collected using a vibratome. Tissue samples from the spleen, thymus, and esophagus were collected as well. All tissue samples were placed on culture inserts (Millipore, Billerica, MA, USA) and placed in a $35-\mathrm{mm}$ petri dish containing $1.2 \mathrm{ml}$ of culture media, as described in Guenthner et al. (2009). Rhythms in bioluminescence were monitored using a Lumicycle (Actimetrics Inc., Wilmette, IL, USA). We compared aged mice housed without running wheels to aged and young mice housed with running wheels. Of the 111 animals used in the first experiment, mice were distributed to conditions as follows: aged mice housed without running wheels: controls: $n=9$, Day 4: $n=8$, Day 9: $n=5$; aged mice housed with running wheels: controls: $n=17$, Day 2: $n=12$, Day 4: $n=11$, Day 9: $n=6$; young mice housed with running wheels: controls: $n=10$, Day 2: $n=13$, Day 4: $n=10$, Day 9: $n=6$.

In a second experiment, aged mice (male, $\mathrm{mPer} 2^{\text {luc/+ }}$ and mPer $2^{\text {luc/luc }}, 626$ to 652 days old on the day of euthanasia) were housed individually with a motion sensor positioned on the cage lid. Nine mice were housed with a running wheel and nine mice had no running wheel. Mice were under a LD cycle 12:12 (light intensity: 350-400 lx) for 2 months before receiving a phase advance shift of $8 \mathrm{~h}$. On Day 4 , after the LD shift, eight mice from each group were euthanized and tissues prepared as described above for bioluminescent recording.

Data analysis methods

For electrophysiological data, the average firing rate of each cell recorded from each slice was plotted against the ZT of the recording. Slices without significant differences across firing rate data grouped into 1 (ZT)-h bins $(p<0.05$; Analysis of variance (ANOVA) ) were not used for further analysis $(n=1)$. If there were significant differences, data were smoothed by $1-\mathrm{h}$ running means with a 15-min lag. The time corresponding to the maximum of the smoothed data was used as the time of the peak firing. A significant difference between the two groups $(p<0.05)$ was determined by a $t$ test ( $n=7$ per group).

Activity and bioluminescence time series were analyzed using custom scripts as described in Leise and Harrington (2011), run in MATLAB 7.14.0 (The MathWorks, Natick, MA, USA) and calling routines from the wmtsa package (Charles R. Cornish, http:// www.atmos.washington.edu/ wmtsa/). The discrete wavelet transform (DWT) decomposes a time series into components corresponding to different frequency bands in a time-localized manner, thereby isolating the circadian component to effectively remove trend and noise. This also partitions the variance (energy) of a time series according to the frequency band, so that the circadian component can be quantitatively compared to that of the ultradian components. We applied a translation-invariant DWT with the Daubechies leastasymmetric filter with length of 12 to 4-day-long activity records with $30-$ min bins using periodic boundary conditions and starting and ending in the middle of rest intervals to minimize edge effects. We also applied this DWT to PER2::LUC bioluminescence time series (10-min time steps) to extract the circadian component, which we used to determine times of peak luminescence in tissue explants.

Circular statistics were computed using the CircStat toolbox (Berens 2009). Time in hours was converted to angles in radians by multiplying by $2 \pi / 24$. The circular mean $\theta$ of $n$ angles $\alpha_{k}$ is defined as $\theta=\arg \left(\frac{1}{n} \sum_{k=1}^{n} e^{i \alpha_{k}}\right)$, while the circular standard deviation is defined as $s=\sqrt{-2 \ln r}$, where $r$ is the synchronization index $r=\left|\frac{1}{n} \sum_{k=1}^{n} e^{i \alpha_{k}}\right|$.

To calculate the rhythmicity index (RI), we computed the autocorrelation of 5-day-long bioluminescence time series and set RI to be the value at the second peak (where the lag equals the period). A few samples with outlier RI values (below 0.1 ) were discarded (two SCN, three spleen, 11 esophagus, and one thymus out of 127 total samples for each tissue).

Motion records were normalized for each animal by dividing by the mean value over a 4-day window. 
Actograms were prepared in ClockLab software using scale of 5 for motion sensor data and 25 for wheel data. Multiple comparison ANOVA analyses use Tukey's honestly significant difference criterion.

\section{Results}

Comparison of activity measures under entrained conditions

The SCN output from aged mice with or without wheels was compared using electrophysiological measures. We assessed the value of the firing rate from each slice at the time of the peak of the smoothed curve fit to the data from that slice. Aged mice housed with wheels $(n=7)$ exhibited significantly higher peak firing rate than aged mice without wheels $(n=7): 5.02$ \pm 0.16 versus $4.06 \pm 0.07 \mathrm{~Hz}$ (mean $\pm \mathrm{SEM}, t$ test $p<$ $0.001)$. The time of peak firing rate did not differ between the two groups: ZT $30.3 \pm 0.1$ versus $\mathrm{ZT}$ $30.4 \pm 0.1$ (mean \pm SEM, $t$ test $p=0.19$ ). See Fig. 1 for representative examples.

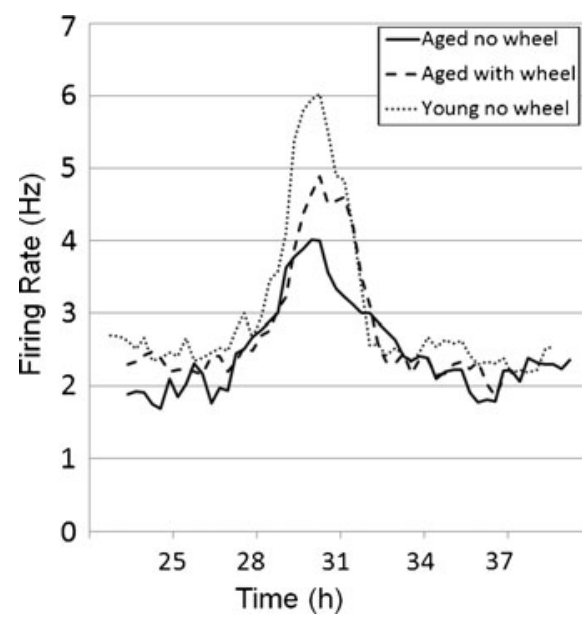

Fig. 1 Frequency of SCN cell firing rates represented by a 1$\mathrm{h}$ running mean with a 15 -min lag over time for representative slices recorded from two aged mice, one housed with and one housed without a wheel. Data from a representative young mouse has also been included for reference. Zeitgeber Time (ZT) 12 is defined as the time of lights off in the animal's previous light:dark cycle, so the trace shows data obtained from recordings over $12 \mathrm{~h}$ in vitro. As is evident from the representative traces shown here, there was no difference between the mean peak times slices from aged mice house with or without a running wheel, although there was a significant difference in amplitude such that slices recorded from older mice without a wheel showed attenuated amplitude. (Biello 2009)
The median patterns of normalized locomotor activity were comparable in aged mice and younger mice in the baseline condition of entrainment to LD12:12 (see Fig. 2a). However, aged mice wheel-ran significantly less than young mice: $26 \pm 15$ versus $65 \pm 19$ mean wheel revolutions per half-hour bin (mean \pm $\mathrm{SD}, t$ test $p<0.001)$. See Fig. 2c. Furthermore, the strength of circadian rhythmicity differed across the groups, as measured by energy separated into frequency bands by a DWT (Leise and Harrington 2011) for both motion and wheel-running activity (see Fig. 2b, d). In particular, aged mice exhibit greater fragmentation of activity than young mice, as indicated by the values in Fig. $2 b$ for the energy in the scale 1, corresponding to the time scale $0-3 \mathrm{~h}(p<0.001, F=$ 41 , multiple comparison test). The energy in scales $2-$ 4 (3-16 h, corresponding to ultradian motion patterns) is similar in young and aged mice, with or without a wheel, but is quite different in the circadian scale 5 ( $p$ $<0.001, F=37$, multiple comparison test), indicating a weakened circadian rhythm in the activity of aged mice. Both the reduced overall activity and increased fragmentation of activity for aged mice are consistent with previous findings (Valentinuzzi et al. 1997), as is the delayed onset of activity at lights off for aged mice, shown in Fig. 2c.

We also examined an alternative measure, the RI (value of the autocorrelation sequence at lag=24 h) of activity rhythms. The RI of motion under entrained LD 12:12 conditions had a mean differing significantly among the three groups $(p<0.001, F=25$, multiple comparison test) and was positively correlated $(r=$ $0.78, p<0.001)$ with the proportion of circadian energy for the DWT. RI $<0.083$ indicates that the motion record did not exhibit significant circadian rhythmicity. Motion records for $100 \%$ of young mice were significantly rhythmic (RI $0.42 \pm 0.02$, mean \pm SEM), $93 \%$ of aged mice with wheel (RI $0.30 \pm 0.02), 77 \%$ of aged mice without wheel (RI $0.19 \pm 0.03$ ), compared to $100 \%$ of wheel records of young and aged mice (RI $0.63 \pm 0.01$ and $0.48 \pm 0.02$, respectively).

Differences in response to an $8 \mathrm{~h}$ advance of the LD cycle

Following the $8 \mathrm{~h}$ advance of the LD cycle, the aged mice required more days than young mice to adjust their locomotor activity rhythms to a typical phase relative to dark onset, as is shown for wheel-running 
a
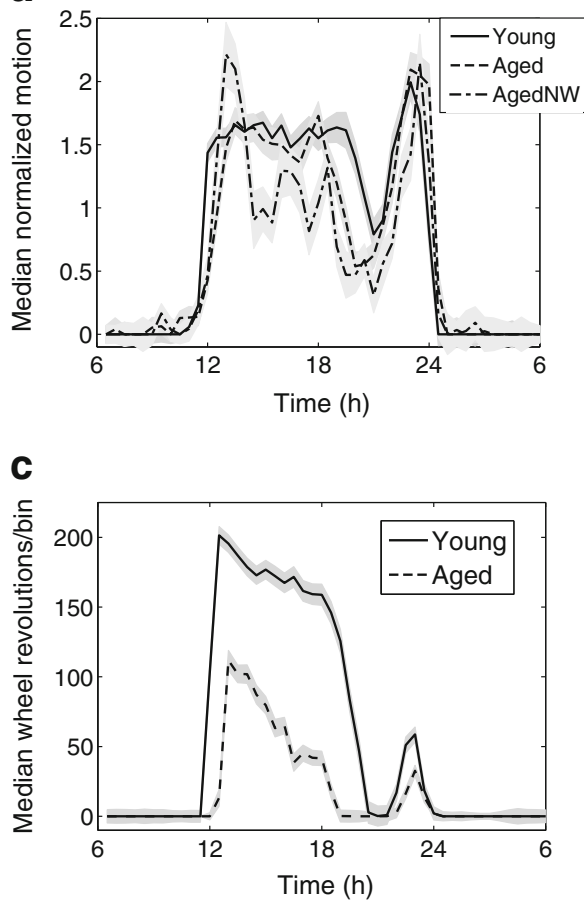

Fig. 2 Analysis of activity under control conditions: a median normalized motion under LD12:12. Gray band indicates the standard error of the median. b Proportion of energy in discrete wavelet transform (DWT) scales of motion, which can be interpreted as proportion of variance accounted for by each period range. All three groups are signficantly different in proportion of energy in level $k=1$ and in circadian level $k=5(p<0.001)$ but

rhythms in Figs. 3 and 4. On Day 3, only one out of 16 aged mice with wheels displayed activity onset within $2 \mathrm{~h}$ of the expected value (based on the preshift time of onset), compared to ten of 16 young mice. On Day 5, zero of six aged mice had accomplished this, compared to five of six young mice. By Day 9, six out of six mice in each group had shifted to within $1 \mathrm{~h}$ of the expected value. Aged mice housed with a running wheel typically displayed greater circadian rhythmicity in motion sensor actograms during re-entrainment (see a representative example in Fig. 5a) than did aged mice housed without a running wheel (Fig. 5b). As shown in Fig. 6, the pattern of wheel use was altered on Days 1-3 following the shift, especially in the aged mice. By Day 5 postshift, young mice display activity patterns consistent with baseline wheel use, whereas aged mice continued to show altered patterns of wheel use and lower levels of wheel use early in the dark phase compared to baseline patterns. b

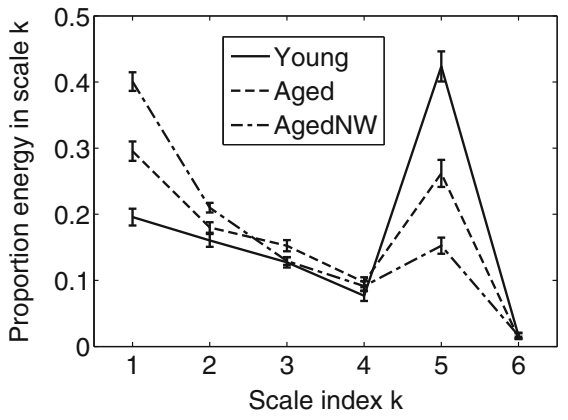

d

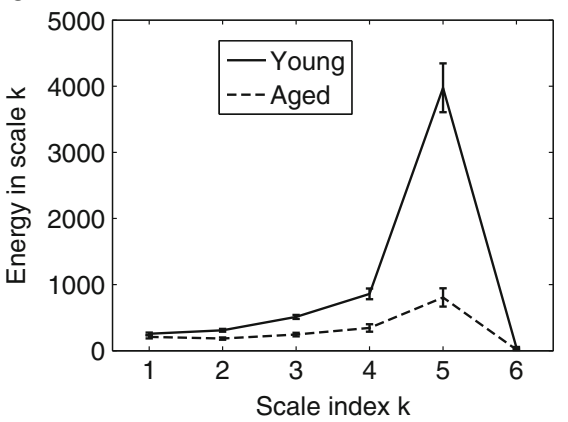

not significantly different for levels $k=2,3$, and 4 (multiple comparison test). c Median wheel revolutions per 30-min bin. d Energy in DWT scales for wheel-running activity. Young mice had greater magnitude of overall activity and much greater energy in the circadian scale $k=5$. In $\mathbf{b}$ and $\mathbf{d}$, error bars show mean \pm SEM. $N W$ signifies animals housed without access to a running wheel

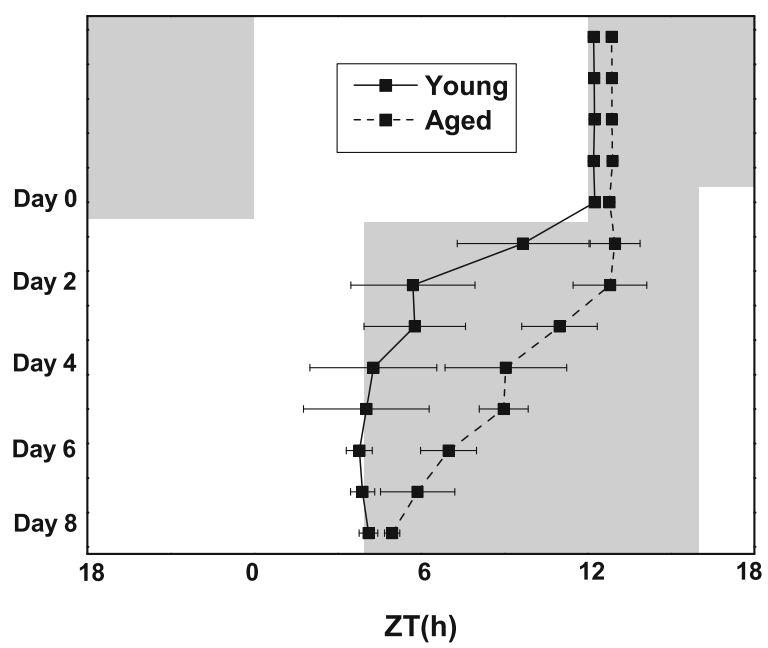

Fig. 3 Young and aged mice housed with running wheels showed different rates of re-entrainment of wheel-running activity rhythms to the shifted LD cycle. Circular means with $95 \%$ confidence intervals for the circular mean 

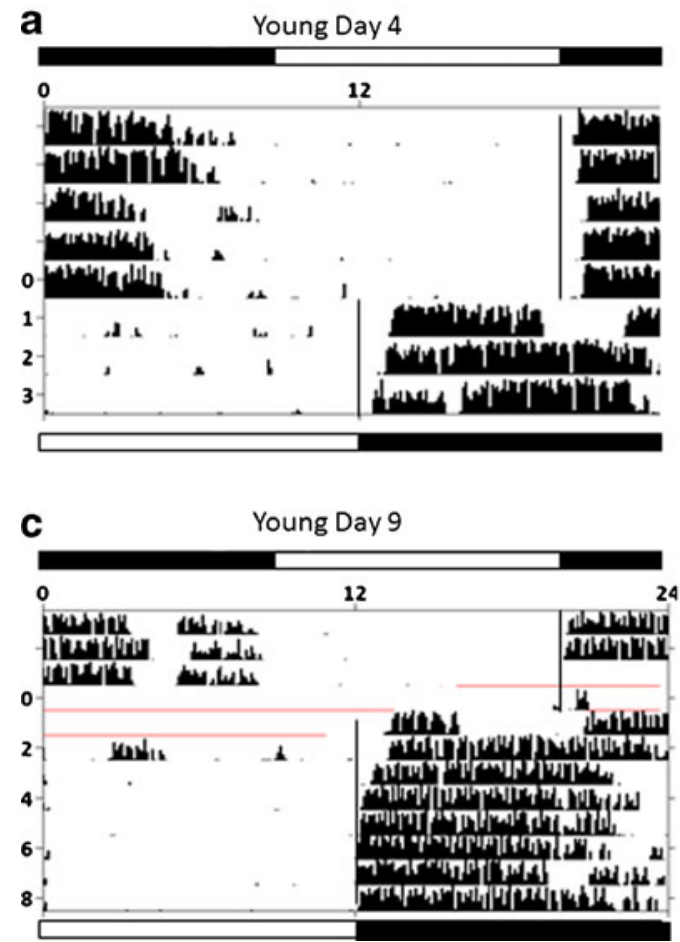

Fig. 4 Example actograms showing both less wheel use in aged mice (b and d) as well as slowed response to the shifted light: dark cycle. Animals shown in $\mathbf{a}$ and $\mathbf{b}$ were euthanized on Day 4

We examined mPER2::LUC bioluminescence rhythms of four tissues (SCN, esophagus, spleen, and thymus) of young and aged mice taken on Days 2, 4, and 9 following the $8 \mathrm{~h}$ advance of the LD cycle. For aged mice without a wheel, samples were taken on Days 4 and 9 (not Day 2). As detailed below, our analysis shows that in response to the $8 \mathrm{~h}$ advance, rhythmicity

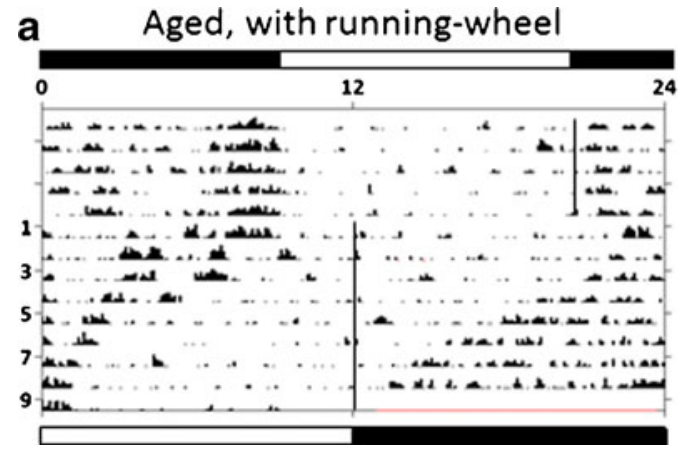

Fig. 5 Motion sensor actograms in aged mice a with and $\mathbf{b}$ without access to a running wheel. Vertical lines show time of dark onset in the LD 12:12 cycle. Motion sensors were
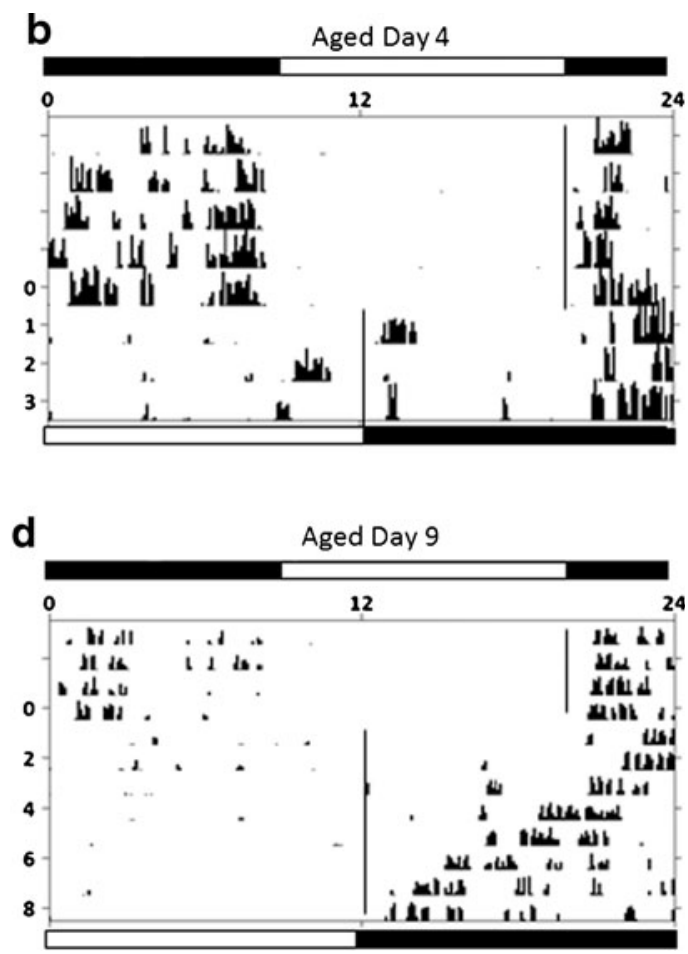

postshift, and actograms $\mathbf{c}$ and $\mathbf{d}$ were from mice euthanized on Day 9. Vertical line indicates time of lights off in the 12:12 LD cycle. Horizontal lines indicate missing data

was reduced and the number of days needed to achieve the shift was increased in aged mice, with a greater effect for aged mice without a wheel.

The amplitude of PER2::LUC oscillations in SCN explants did not differ significantly between young and aged mice, with or without wheels, prior to the shift, and it decreased in response to the LD shift, with

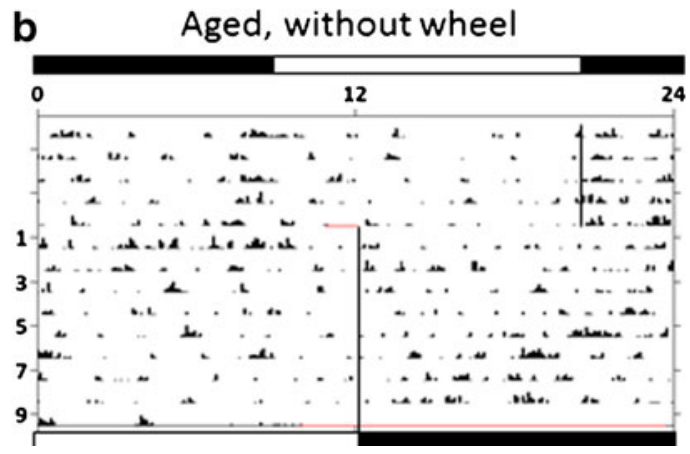

positioned to pick up activity in the area of the cage under the water bottle and to only minimally pick up activity in the running wheel 
Fig. 6 Comparison of aged and young mice in wheel use patterns. Mean wheel revolutions were summarized in 30min bins. Mice from Day 9 groups in aged $(n=4)$ and young $(n=6)$ mice

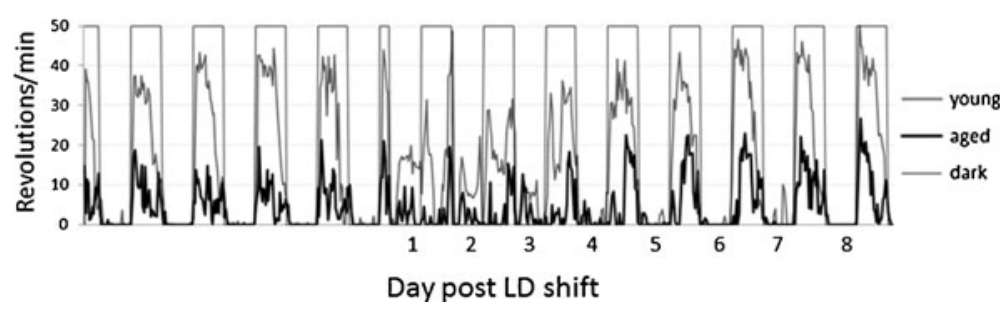

longer-lasting effects in aged mice. In young mice, SCN amplitude was significantly lower only on Day 2, while in aged mice, it was lower on both Days 2 and 4 compared to preshift control and Day 9 conditions $(p<$ 0.001 , multiple comparison test). For aged mice without wheels, SCN amplitude on Day 4 was also significantly lower than the preshift control $(p=0.001)$. See Fig. 7. To assess the regularity of oscillations, we used the RI; see Fig. 8 for an explanation of RI. Mean RI of SCN explants for young and aged mice did not differ significantly before or on Day 2 of the $8 \mathrm{~h}$ advance ( $p=0.1$, multiple comparison test). On Day 4, SCN RI of young mice were not significantly different from controls, but that of aged mice was significantly lower, indicating disrupted or weakened rhythms in the SCN $(p<0.001$, $F=14$, multiple comparison test). On Day 9, the SCN RI of all three groups were significantly different from each other ( $p<0.001, F=22$, multiple comparison test), with SCN RI of aged mice still significantly below that of young mice, and the SCN RI for aged mice without wheels was significantly less than that for aged mice with wheels (see Fig. 9a).

The SCN of young mice re-entrained in fewer days than those of aged mice (see Fig. 10). On Day 2, both young and old mice exhibited disrupted SCN phases.

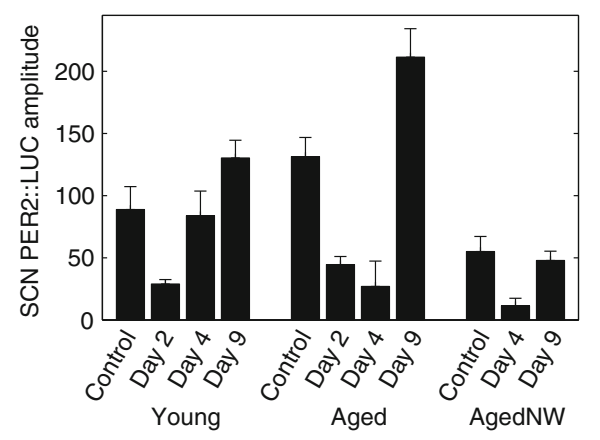

Fig. 7 Amplitude of PER2::LUC oscillations in SCN explants. Bioluminescence time series were first detrended and then amplitude was calculated as the difference between maximum and minimum brightness (in counts per second) on the second cycle in vitro. Error bars show mean $\pm \mathrm{SEM}$
On Day 4, the SCN of the majority of young mice had nearly completed the $8 \mathrm{~h}$ advance (eight of ten were within $2 \mathrm{~h}$ of the expected value, based on control peak times), but the aged mice continued to exhibit disrupted phases. By Day 9, the SCN of mice in all three groups had completed the $8 \mathrm{~h}$ advance (mean did
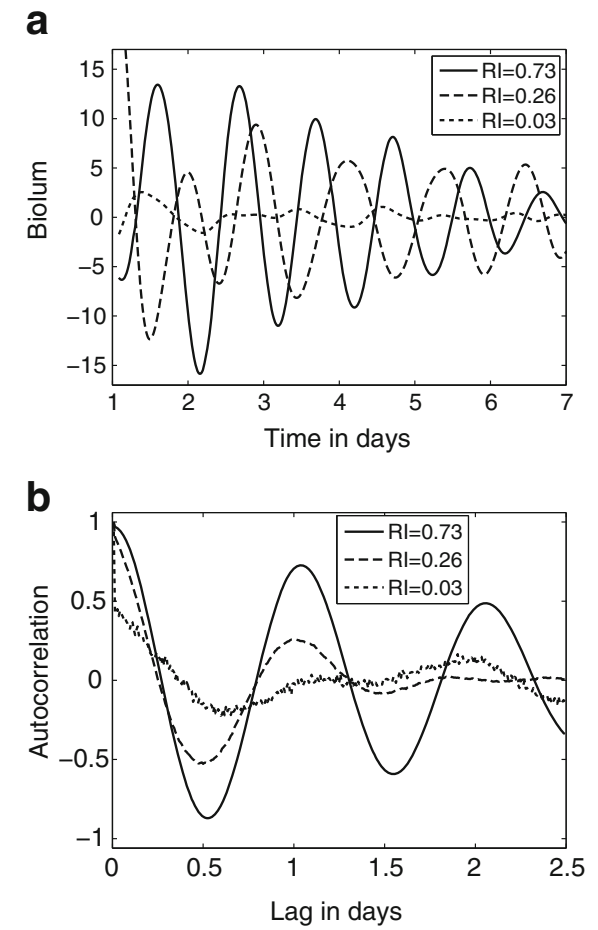

Fig. 8 Explanation of rhythmicity index (RI). a Three bioluminescence recordings of SCN explants from young mice dissected on Day 2, with noise and trend removed for clarity of comparison. The time series $(4,189)$ with $\mathrm{RI}=0.73$ exhibits more regular waveforms and peak-to-peak intervals (SD $0.6 \mathrm{~h}$ ) than the time series $(4,118)$ with $\mathrm{RI}=0.26$ (SD $3.6 \mathrm{~h}$ ). The time series with $\mathrm{RI}=0.03$ is not significantly rhythmic. b The autocorrelation gives the correlation of a time series with lagged version of itself, so that a periodic time series will have a peak in its autocorrelation when the lag equals the period. This peak value is the RI for these bioluminescence time series. A perfectly periodic time series has $\mathrm{RI}=1$, while $\mathrm{RI}$ below $2 / \operatorname{sqrt}(N)$, where $N$ is the number of time points, indicates an arrhythmic time series 
a

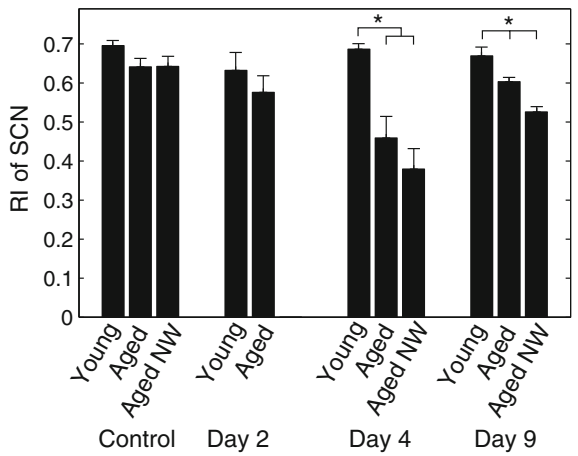

Fig. 9 Rhythmicity of SCN explants and desynchrony in tissue explant phases in response to $8 \mathrm{~h}$ advance of LD cycle. a The regularity of rhythms exhibited by SCN explants, measured by rhythmicity index (RI), does not differ significantly in mean between young, aged, and aged NW mice for LD12:12 control condition $(p=0.14)$ or on Day 2 between young and aged mice $(p=0.87)$. $N W$ animals housed without access to a running wheel. On Day 4, young mice had a mean RI that did not differ significantly from the control value, while for aged and aged NW mice, the mean RI was significantly different from that for young Day 4 and all of the controls $(p<0.001, F=12$, multiple comparison test). All three groups differed significantly on Day $9(p<0.001, F=22$, multiple comparison test). b Desynchrony of phases of the SCN, spleen, esophagus, and thymus is measured b

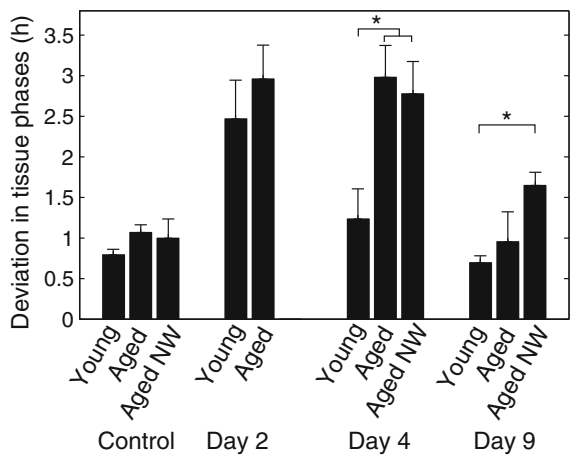

by taking the circular standard deviation of the tissue phases relative to the average phase relations under control conditions. Variability among individuals leads to some deviation from average for the control group. The desynchrony is significantly greater for both young and aged mice with wheels on Day 2 than for the control group, while on Day 4, desynchrony is not significantly different from control values for young mice but remains signficantly different for aged mice $(p<0.001, F=6.9$, multiple comparison test comparing control, Day 2, and Day 4 conditions). On Day 9, desynchrony of aged mice without wheels remains significantly higher in mean than that of young mice ( $p=0.01$, one-sided $t$ test), but desynchrony of aged mice with wheels is not significantly different from that of young mice. ${ }^{*} p<0.01$. Error bars show mean \pm SEM not differ significantly from expected value). Another measure of internal temporal order is to examine the relative phase of the last activity onset and the time of peak of the SCN ex vivo. When we examined these phase relationships, we found that control unshifted mice and mice on Day 9 postshift showed similar phase relationships between SCN and locomotor activities (see Fig. 11 and Supplementary 1). Mice euthanized 2 days after the LD shift showed disruption of this internal phase synchrony. In young mice, internal synchrony between locomotor activity and SCN mPER2::LUC rhythms was largely restored by Day 4

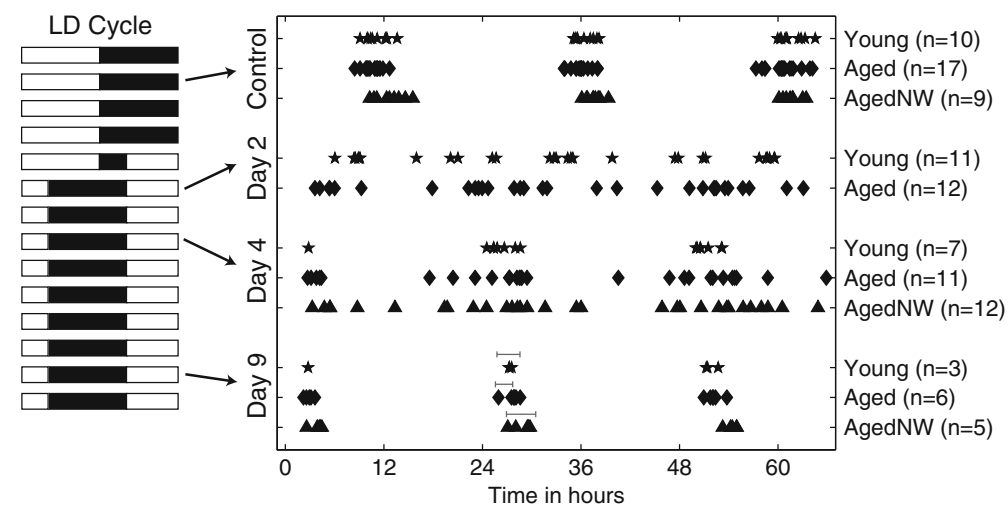

Fig. 10 Peak times of PER2::LUC recordings of SCN explants over 3 cycles in vitro. Time in hours is given relative to ZT of unshifted LD cycle (so PER2 in control mice peaks near time of lights off). Time 0 is the beginning of the second day in vitro. Gray bars on Day 9 indicate expected phase based on mean \pm SD of controls. $N W$ animals housed without access to a running wheel 

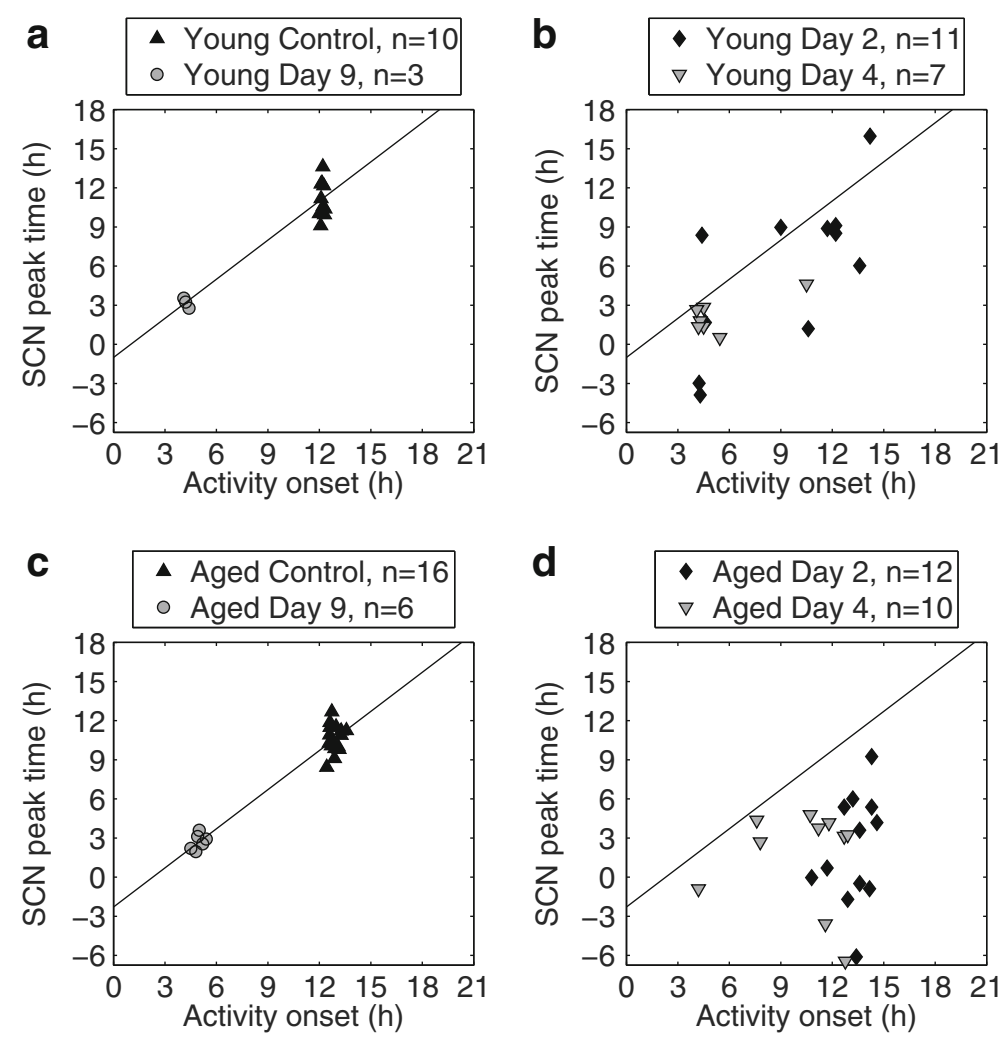

Fig. 11 The time of the peak of the PER2::LUC rhythm of the $\mathrm{SCN}$ in vitro was predictably related to the time of last wheelrunning activity onset in control unshifted animals (black triangles) as well as animals 9 days after the LD shift (gray circles) in both young (a) and aged (c) mice. Mice euthanized 2 days after the LD shift (black diamonds) showed disruption of this internal phase synchrony. In young mice,

postshift, whereas aged mice continued to demonstrate disrupted internal synchrony on Day 4.

Peripheral tissues in aged mice tended to require more days to complete the shift in response to the $8 \mathrm{~h}$

internal synchrony between locomotor activity and SCN Per2::Luc rhythms was largely restored by Day 4 postshift (gray inverted triangles, b) whereas aged mice continued to demonstrate disrupted internal synchrony on Day 4 (gray inverted triangles, d). In all graphs, lines have slope 1 and pass through the centroid of the control data points (black triangles) for the respective age group

advance, with only a modest shift by Day 4, while in young mice, most of the shift was accomplished by Day 4 (see Table 1). Young mice shifted significantly more than aged mice on Day 4 for all three peripheral

Table 1 Shifting of peripheral tissues in response to $8 \mathrm{~h}$ advance of LD cycle. Peak time of PER2:: LUC for peripheral tissues is given as hours relative to $\mathrm{ZT}$ of the original LD cycle. Positive shift indicates advancing of phase; negative shift indicates delaying of phase. Peak time and shifts are stated as circular mean \pm circular standard deviation in hours. $N W$ groups without access to a running wheel

\begin{tabular}{llrrrr}
\hline Tissue & Group & Control peak time & Shift on Day 2 & Shift on Day 4 & Shift on Day 9 \\
\hline \multirow{2}{*}{ Thymus } & Young & $19.5 \pm 1.1 \mathrm{~h}$ & $2.5 \pm 1.3 \mathrm{~h}$ & $6.3 \pm 2.2 \mathrm{~h}$ & $7.9 \pm 0.9 \mathrm{~h}$ \\
& Aged & $18.6 \pm 1.3 \mathrm{~h}$ & $0.6 \pm 1.4 \mathrm{~h}$ & $2.1 \pm 1.8 \mathrm{~h}$ & $8.6 \pm 2.7 \mathrm{~h}$ \\
& Aged NW & $18.2 \pm 1.0 \mathrm{~h}$ & & $1.0 \pm 1.6 \mathrm{~h}$ & $7.0 \pm 2.6 \mathrm{~h}$ \\
\multirow{5}{*}{ Spleen } & Young & $18.6 \pm 1.1 \mathrm{~h}$ & $0.6 \pm 1.0 \mathrm{~h}$ & $7.3 \pm 1.7 \mathrm{~h}$ & $9.0 \pm 0.9 \mathrm{~h}$ \\
& Aged & $18.5 \pm 1.4 \mathrm{~h}$ & $-0.1 \pm 1.2 \mathrm{~h}$ & $1.5 \pm 2.5 \mathrm{~h}$ & $8.4 \pm 1.1 \mathrm{~h}$ \\
& Aged NW & $19.5 \pm 0.7 \mathrm{~h}$ & & $2.0 \pm 2.6 \mathrm{~h}$ & $10.3 \pm 1.7 \mathrm{~h}$ \\
Esophagus & Young & $18.7 \pm 0.5 \mathrm{~h}$ & $2.4 \pm 0.9 \mathrm{~h}$ & $6.6 \pm 1.4 \mathrm{~h}$ & $9.3 \pm 0.5 \mathrm{~h}$ \\
& Aged & $17.7 \pm 1.4 \mathrm{~h}$ & $0.6 \pm 2.6 \mathrm{~h}$ & $2.9 \pm 2.3 \mathrm{~h}$ & $8.0 \pm 2.5 \mathrm{~h}$ \\
& Aged NW & $17.5 \pm 1.2 \mathrm{~h}$ & & $0.8 \pm 1.4 \mathrm{~h}$ & $7.7 \pm 1.1 \mathrm{~h}$ \\
\hline
\end{tabular}


tissues. The shift of the esophagus in aged mice with a wheel was significantly more than that of aged mice without a wheel by Day 4 ( $p=0.02, t$ test), while the shift of the thymus was only marginally greater ( $p=$ $0.07, t$ test). The shift of the spleen showed no significant difference on Day 4 between aged mice with and without a wheel ( $p=0.65, t$ test).

Internal desynchrony of the phases of the four tissues also lasted longer for aged mice without a wheel, as shown in Fig. 9b. On Day 2, both young and aged mice exhibited significantly increased internal desynchrony as measured by circular standard deviation of the tissue phases from the average relative phases under control conditions, while on Day 4, desynchrony among the tissues of aged mice with and without wheels remained high but that of young mice was not significantly different from controls $(p<0.001, F=6.9$, multiple comparison test comparing control, Day 2, and Day 4 conditions). On Day 9, aged mice without a wheel exhibited internal desynchrony among tissues greater than that of young mice ( $p=0.02, t$ test), while that of aged mice with wheels did not differ significantly from the other two groups. We observed no significant difference in amplitude of the PER2::LUC oscillations in peripheral tissues across the conditions.

We compared results from aged mice when euthanized early in the light period versus late in the light period. All mice in this sample were housed with wheels. Unlike similar experiments with younger mice (Davidson et al. 2009), we found several differences due to time of dissection. For the SCN, morning dissection time resulted in peak times, on average, $1.3 \mathrm{~h}$ earlier (means significantly different, $p=0.007$ ), but no significant difference in RI $(p=0.70)$. For esophagus samples, morning dissection time resulted in later peak times $(p=0.045)$ but no significant difference in RI $(p=0.84)$. For spleen, there was no difference in the mean peak times $(p=0.47)$, but peak times appeared more variable with evening dissection time, and the two samples differed in mean RI $(p<$ $0.001)$. For thymus, there was no effect of dissection time $(p=0.75)$, but the mean of RI was significantly different $(p=0.036)$. For spleen and thymus, rhythms were better (as quantified by the RI) if dissected in the afternoon.

In our second bioluminescence experiment, we aimed to replicate findings from the first experiment indicating differences in aged mice housed with or without a wheel. The mice in this second experiment were significantly older than the mice in the first experiment $(p<0.001)$. We replicated the results shown in Fig. 2, finding that the strength of circadian rhythmicity differed across the groups, as measured by energy separated into frequency bands by a DWT. The proportion of the energy in the circadian component (scale 5) from our replication was nearly identical to that found in the first experiment (see Fig. 2b) with the aged mice with wheels showing $0.23 \pm 0.02$ and the aged mice without a wheel averaging $0.15 \pm 0.03$, with means significantly different $(p=0.03)$. As in the first experiment, aged mice with or without wheels exhibited reduced RI of the SCN on Day 4 following the LD shift that was not significantly different between the two groups $(p=0.46)$. The phase shift of the $\mathrm{SCN}$ and peripheral tissues was also not significantly different between these two groups, and none of the peripheral tissues shifted in phase by an appreciable amount, although we noted that the aged mice without wheel access showed greater variability in phase when compared to the mice with wheel access (e.g., circular standard deviations for the phase shifts of the four tissues for the no wheel mice were 3.0-3.4 h, while those for tissues of the with-wheel mice range from 1.1 to $1.9 \mathrm{~h}$ ). This result differs from the data from the first experiment shown in Table 1. The aged mice in the second experiment used their running wheels less than those in the first experiment $(19 \pm 11$ versus $26 \pm$ 15 revolutions, mean $\pm \mathrm{SD}, t$ test $p=0.002)$. They also differed in the average duration of wheel use during the subjective night, with the aged mice in the second experiment showing shorter duration activity period than the aged mice in the first experiment.

\section{Discussion}

Our experiments have demonstrated that male mice show several changes in their circadian system as they age. We replicated previous reports that aging is associated with reduced use of the running wheel, fragmentation of activity under a stable LD cycle, and slowed phase resetting following a shift in the LD cycle. We demonstrate here that, following a shift of the LD cycle, both young and aged mice exhibit reduced strength of mPER $2:$ LUC rhythms of the $\mathrm{SCN}$ in vitro. This impact of the LD shift on the ability of the SCN to sustain a robust rhythm persists for more days following the shift in aged mice. Both 
behavioral and molecular measures from SCN and target tissues were slower to resynchronize their phase to a shifted LD cycle in aged animals. Access to a running wheel was able to alleviate most of these agerelated changes in the circadian system dynamics. Aged mice housed with a running wheel showed stronger circadian rhythms in locomotor activity, faster recovery of internal synchrony following a LD shift, and increased amplitude of the firing rate rhythm when compared to aged mice housed without a running wheel. The impact of voluntary exercise on circadian rhythm output in an aged animal is a novel finding and has implications for the health of older people living with environmentally induced circadian disruption.

Age-associated reduction in the strength of circadian rhythms was observed in our data through several measures. The DWT (Leise and Harrington 2011) decomposes the energy in locomotor activity recordings into distinct frequency bands, revealing an effect of age that was partially alleviated by the presence of the wheel (see Fig. 2). In particular, aged mice exhibited reduced circadian rhythmicity and increased fragmentation of activity that was worsened by lack of a wheel. Application of RI to motion records also indicated weaker circadian rhythms of activity in aged mice, especially those without a wheel. We further used the RI to assess regularity of circadian oscillations in bioluminescent recordings, demonstrating an impact of a shifted LD cycle on the quality of the circadian rhythm expressed by the SCN in vitro. Normal rhythmicity of the SCN mPER2::LUC oscillation was restored more rapidly in young mice than in aged mice. Young mice also synchronized behavioral activity and peripheral tissue mPER2::LUC rhythms more rapidly, with the difference between young and aged on Day 9 following the LD shift widened by lack of a wheel. Our data fits well with previous experiments, indicating that induced activity continues to influence the functioning of the circadian system in both rodents and humans well into old age (Mrosovsky and Biello 1994; Baehr et al. 2003).

Loss of a strong rhythmic signal from the SCN would be expected to disrupt circadian system synchrony and the ability to reset to a shifted LD cycle. Resetting is accompanied by a period of reduced synchrony among neurons in the SCN in young animals (Davidson et al. 2009; Nagano et al. 2003; Nakamura et al. 2005) and from our results, we hypothesize that this time period is longer in aged animals. Whereas mPER2::LUC rhythms were not different in unshifted mice of different ages in our sample, a result similar to previously published studies (Nakamura et al. 2011), the shift of the LD cycle revealed a weakness in the dynamics of the circadian system in aged animals. We demonstrate that this weakness leads to an extended period of internal desynchrony in the aged mice, in which the SCN and target tissues took longer to adapt to the new phase of the LD cycle. Sellix et al. (2012) found that some peripheral tissues respond more slowly to an LD shift in older mice, which they attribute to an age-related decrease in pacemaker output amplitude, such as would occur with reduced amplitude electrophysiological rhythms.

The decreased rhythmic output signal is evidenced by the lower amplitude of the circadian rhythm in firing rate from aged mice observed in our study. This lower amplitude has been reported by other recording in vivo (Nakamura et al. 2011), in vitro (Biello 2009; Farajnia et al. 2012; Satinoff et al. 1993; Watanabe et al. 1995), and in cultured SCN (Aujard et al. 2001). The observed decrease could be caused by changes in the properties of single cells or by desynchrony in populations of cells. Studies show changes in the neuronal neurotransmitter chemistry of the aging SCN, with decreases in neurotransmitters such as vasoactive intestinal peptide, gastrin-releasing peptide, neurotensin, and vasopressin (Duncan et al. 2010; Swaab et al. 1985). Patch recordings show changes in the membrane properties of SCN neurons that could lead to changes in neuronal communication (Farajnia et al. 2012).

Perhaps the most significant changes occur with the major inhibitory neurotransmitters of the SCN, Gammaaminobutyric acid (GABA), which is thought to be important for the network of cellular communication within the SCN in both young and aged mice (Albus et al. 2005; Biello 2007). In addition, endogenous GABA is thought to play a role specifically in maintaining the amplitude of the SCN (Aton et al. 2006). There are changes to the GABAergic system with age including an age-related decrease of GABAergic terminal area in the mouse SCN. Alterations are seen both in the presynaptic network of GABA terminals (Palomba et al. 2008) and GABAergic current amplitude (Farajnia et al. 2012) in aged animals. These changes in the GABAergic system within the SCN have consequences observable as changes to functional response to the 
GABA signal with age (Biello 2009). These alterations to the system could contribute to variations in neuronal communication within the SCN with age. Alterations to the neurotransmitters underlying these effects may become particularly important in potential applications of this work. Not all older individuals may be in a position to take advantage of exercise as a route to improve synchrony, and a more complete understanding of the system physiology may aid in the development of pharmacological tools.

These changes in SCN communication suggest that, in addition to decreased output signals from the $\mathrm{SCN}$, deterioration of other aspects of the circadian system may occur with aging. The SCN of the older mice (22-28 months) used in Sellix et al. (2012) shifted more rapidly than those of young mice or the aged mice (18-20 months) used in our study and also experienced greater phase desynchrony among SCN neurons than young mice following the LD shift. These differences could potentially be due to deficits in communication among SCN neurons worsening with age, so that in very old mice, the SCN has a greatly weakened network in which the phases of neurons are easily shifted. For instance, the modeling and experimental work of Abraham et al. (2010) suggests that SCN networks with reduced coupling respond more readily to entrainment signals. Degradation of input signals to the SCN is also likely to occur with aging. A weakened photic input signal in aged animals is one potential cause of the slowed response to shifts of the LD cycle in aged animals that we observed. Older animals like those studied in Sellix et al. (2012) may additionally experience significantly reduced coupling among SCN neurons, which could then respond with large phase changes even to a reduced input signal. Deficits in the output signals from the SCN associated with aging would result in a slowed response of peripheral tissues and activity to a shift of the LD cycle.

We found that a running wheel can boost the firing rate in the SCN; however, the mechanism by which the wheel or exercise might improve circadian organization is not clear. We see several possibilities from the current literature. Intracranial implants of fetal SCN tissue have been shown to improve circadian rhythms in older rats with poor circadian rhythms ( $\mathrm{Li}$ and Satinoff 1998), suggesting that downstream targets are capable of responding to a stronger circadian clock signal in aged animals. Transitions between vigilance states have been shown to be mirrored by alterations in SCN firing rate (Deboer et al. 2003). Wheel running in mice has been shown to increase firing of neurons within the SCN, which would have an impact on amplitude (Schaap and Meijer 2001; Yamazaki et al. 1998). Additionally, wheel running has also been shown to improve the consolidation of the circadian activity patterns in mice with impaired SCN function (Power et al. 2010). Therefore, it is possible that the running wheel was able to improve circadian activity rhythms via increasing the amplitude of firing of SCN cells.

Whereas a prior study reported that older mice showed increased locomotor activity in the late portion of the dark phase, a result compared to the clinical instance of "sundowning" in Alzheimer's patients, where agitation and dementia symptoms are worse in the late afternoon (Bedrosian et al. 2011), we failed to replicate this effect, as did a study using CD1/129 mice between 4 and 15 months of age (Duncan et al. 2012). These and our studies differ in the strain and age of the mice, with the study showing "sundowning" comparing C57BL/6 mice of 7 and 29 months and housing them under an LD of 14:10 (Bedrosian et al. 2011).

There are several limitations to our approach for measuring circadian parameters from tissues ex vivo. One concern is that the dissection might reset the phase of the rhythms. This has been observed in some studies (Gillette 1986; Yoshikawa et al. 2005) but has not been observed in all studies (Davidson et al. 2009; vanderLeest et al. 2009; Yannielli and Harrington 2000). In our lab, we have demonstrated for male and female young adult mPer $2^{\text {Luc }}$ mice housed in 12:12 LD cycles that dissection between ZT 2 and 10 does not reset phase for SCN, spleen, esophagus, thymus, and lung (Davidson et al. 2009). Here, we demonstrate no sizable difference in phase between aged male mPer2 ${ }^{\text {Luc }}$ mice housed in 12:12 LD cycles for SCN, thymus, and spleen when dissected either between ZT 2and 3 or ZT 10 and 11, but for some tissues, we did find statistically significant differences in phase depending on time of dissection in the aged mice. When choosing the dissection phase for mice in the groups experiencing a shift of the LD cycle, we timed this to occur within an hour of ZT 2-10 in both the original and the shifted cycle. We do not know if the mice in a state of circadian desynchrony following a shift of the LD cycle respond to dissection in the 
same way as do the mice in the control unshifted conditions. To continue this work, one possibility would be to use in vivo imaging of rhythms from SCN and peripheral tissues, as in Tahara et al. (2012).

A reduction in circadian rhythm consolidation and internal desynchrony has been linked with disrupted sleep and negative health consequences, with multiple impacts on age-related pathologies (Kondratova and Kondratova 2012). Diverse lines of research link circadian disruption and cancer incidence and progression (Greene 2012) and cardiovascular disease (Martino and Sole 2009). Metabolism is intricately regulated by the circadian clock and internal temporal disorder contributes to obesity and metabolic disorders (Albrecht 2012). Aged mice subjected to 8 weeks of weekly $6 \mathrm{~h}$ advances of the LD cycle showed significantly increased mortality; the control group showed $83 \%$ survival, while the disrupted group had only $47 \%$ survival and when advances occurred every 4 days, the mortality increased (Davidson et al. 2006). Further research that allows us to better address circadian disruption will have wide implications for health and lifespan of aging populations. Our research opens new research vistas in that our studies suggest that increased voluntary exercise can have beneficial effects on circadian disruption in aged mice. Further research is necessary to better establish and to detail mechanisms for these effects of exercise on circadian health in aging.

Acknowledgments We are grateful for financial support from EARDA NIH funds (Smith College). A portion of this work was supported by NIH R21NR012845. We are also grateful to Research into Ageing (UK) and the Wellcome Trust (UK) for funds that supported portions of the experimental work.

Open Access This article is distributed under the terms of the Creative Commons Attribution License which permits any use, distribution, and reproduction in any medium, provided the original author(s) and the source are credited.

\section{References}

Abraham U, Granada AE, Westermark PO, Heine M, Kramer A, Herzel H (2010) Coupling governs entrainment range of circadian clocks. Mol Syst Biol 6:438

Albrecht U (2012) Timing to perfection: the biology of central and peripheral circadian clocks. Neuron 74:246-260

Albus H, Vansteensel MJ, Michel S, Block GD, Meijer JH (2005) A GABAergic mechanism is necessary for coupling dissociable ventral and dorsal regional oscillators within the circadian clock. Curr Biol 15:886-893
Ancoli-Israel S, Alessi C (2005) Sleep and aging. Am J Geriatr Psychiatr 13:341-343

Asai M, Yoshinobu Y, Kaneko S, Mori A, Nikaido T, Moriya T, Akiyama M, Shibata S (2001) Circadian profile of Per gene mRNA expression in the suprachiasmatic nucleus, paraventricular nucleus, and pineal body of aged rats. J Neurosci Res 66:1133-1139

Aton SJ, Huettner JE, Straume M, Herzog ED (2006) GABA and Gi/o differentially control circadian rhythms and synchrony in clock neurons. Proc Natl Acad Sci U S A 103:19188-19193

Aujard F, Herzog ED, Block GD (2001) Circadian rhythms in firing rate of individual suprachiasmatic nucleus neurons from adult and middle-aged mice. Neuroscience 106:255-261

Baehr EK, Eastman CI, Revelle W, Olson SHL, Wolfe LF, Zee PC (2003) Circadian phase-shifting effects of nocturnal exercise in older compared with young adults. Am J Physiol Integr Comp Physiol 284:R1542-R1550

Bedrosian TA, Herring KL, Weil ZM, Nelson RJ (2011) Altered temporal patterns of anxiety in aged and amyloid precursor protein (APP) transgenic mice. Proc Natl Acad Sci U S A 108:11686-11691

Benloucif S, Masana MI, Dubocovich ML (1997) Light-induced phase shifts of circadian activity rhythms and immediate early gene expression in the suprachiasmatic nucleus are attenuated in old $\mathrm{C} 3 \mathrm{H} / \mathrm{HeN}$ mice. Brain Res 747:34-42

Berens P (2009) Circstat: a MATLAB toolbox for circular statistics. J Stat Softw 31:1-21

Biello SM (2007) Impaired resynchronisation between dorsal and ventral oscillators in SCN with age after a shift in the light:dark cycle. Program No. 927.12. Neuroscience Meeting Planner. San Diego, CA: Society for Neuroscience, 2007. http://www.abstractsonline.com/viewer/ viewAbstractPrintFriendly.asp?CKey $=\{640 \mathrm{~B} 86 \mathrm{E} 7-\mathrm{F} 9 \mathrm{~F} 0$ 4897-90C5-C4AD3B2A6752 $\} \&$ SKey $=\{3622$ AB3D-ED1E481C-8D4F-599FBAFF2D22 $\}$ \&MKey $=\{$ FF8B70E5-B7F94D07-A58A-C1068FDE9D25 $\} \& A K e y=\{3$ A7DC0B9D787-44AA-BD08-FA7BB2FE9004\}

Biello SM (2009) Circadian clock resetting in the mouse changes with age. Age 31:293-303

Buysse DJ, Monk TH, Carrier J, Begley A (2005) Circadian patterns of sleep, sleepiness, and performance in older and younger adults. Sleep 28:1365-1376

Castanon-Cervantes O, Wu M, Ehlen JC, Paul K, Gamble KL, Johnson RL, Besing RC, Menaker M, Gewirtz AT, Davidson AJ (2010) Dysregulation of inflammatory responses by chronic circadian disruption. J Immunol 185:5796-5805

Castillo C, Molyneux P, Carlson R, Harrington ME (2011) Restricted wheel access following a light cycle inversion slows re-entrainment without internal desynchrony as measured in PER2Luc mice. Neuroscience 182:169-176

Cho K (2001) Chronic 'jet lag' produces temporal lobe atrophy and spatial cognitive deficits. Nat Neurosci 4:567-568

Davidson A, Sellix M, Daniel J, Yamazaki S, Menaker M, Block GD (2006) Chronic jet-lag increases mortality in aged mice. Curr Biol 16:R914-R916

Davidson AJ, Yamazaki S, Arble DM, Menaker M, Block GD (2008) Resetting of central and peripheral circadian oscillators in aged rats. Neurobiol Aging 29:471-477

Davidson AJ, Castanon-Cervantes O, Leise TL, Molyneux PC, Harrington ME (2009) Visualizing jet lag in the mouse 
suprachiasmatic nucleus and peripheral circadian timing system. Eur J Neurosci 29:171-180

Deboer T, Vansteensel MJ, Détári L, Meijer JH (2003) Sleep states alter activity of suprachiasmatic nucleus neurons. Nat Neurosci 6:1086-1090

Dijk DJ, Duffy JF, Czeisler CA (2000) Contribution of circadian physiology and sleep homeostasis to age-related changes in human sleep. Chronobiol Int 17:285-311

Duncan MJ, Hester JM, Hopper JA, Franklin KM (2010) The effects of aging and chronic fluoxetine treatment on circadian rhythms and suprachiasmatic nucleus expression of neuropeptide genes and 5-HT1B receptors. Eur J Neurosci 31:1646-1654

Duncan MJ, Smith JT, Franklin KM, Beckett TL, Murphy MP, St. Clair DK, Donohue KD, Striz M, O'Hara BF (2012) Effects of aging and genotype on circadian rhythms, sleep, and clock gene expression in APPxPS1 knock-in mice, a model for Alzheimer's disease. Exp Neurol 236:249-258

Farajnia S, Michel S, Deboer T, vanderLeest HT, Houben T, Rohling JH, Ramkisoensing A, Yasenkov R, Meijer JH (2012) Evidence for neuronal desynchrony in the aged suprachiasmatic nucleus clock. J Neurosci 32:5891-5899

Foley DJ, Monjan AA, Brown SL, Simonsick EM, Wallace RB, Blazer DG (1995) Sleep complaints among elderly persons: an epidemiologic study of three communities. Sleep 18:425-432

Foley DJ, Monjan AA, Simonsick EM, Wallace RB, Blazer DG (1999) Incidence and remission of insomnia among elderly adults: an epidemiologic study of 6,800 persons over three years. Sleep 22:S366-S372

Gillette MU (1986) The suprachiasmatic nuclei: circadian phase-shifts induced at the time of hypothalamic slice preparation are preserved in vitro. Brain Res 379:176-181

Grandner MA, Martin JL, Patel NP, Jackson NJ, Gehrman PR, Pien G, Perlis ML, Xie DW, Sha DH, Weaver T, Gooneratne NS (2012) Age and sleep disturbances among American men and women: data from the US Behavioral Risk Factor Surveillance System. Sleep 35:395-406

Greene MW (2012) Circadian rhythms and tumor growth. Cancer Lett 318:115-123

Guenthner CJ, Bickar D, Harrington ME (2009) Heme reversibly damps PERIOD2 rhythms in mouse suprachiasmatic nucleus explants. Neuroscience 164:832-841

Harrington M, Molyneux P, Soscia S, Prabakar C, McKinleyBrewer J, Lall G (2007) Behavioral and neurochemical sources of variability of circadian period and phase: studies of circadian rhythms of npy-/- mice. Am J Physiol Integr Comp Physiol 292:R1306-R1314

Karatsoreos IN, Bhagat S, Bloss EB, Morrison JH, McEwen BS (2011) Disruption of circadian clocks has ramifications for metabolism, brain, and behavior. Proc Natl Acad Sci U S A 108:1657-1662

Kiessling S, Eichele G, Oster H (2010) Adrenal glucocorticoids have a key role in circadian resynchronization in a mouse model of jet lag. J Clin Invest 120:2600-2609

King AC, Oman RF, Brassington GS, Bliwise DL, Haskell WL (1997) Moderate-intensity exercise and self-rated quality of sleep in older adults. A randomized controlled trial. JAMA 277:32-37

Kolker DE, Fukuyama H, Huang DS, Takahashi JS, Horton TH, Turek FW (2003) Aging alters circadian and light-induced expression of clock genes in golden hamsters. J Biol Rhythm 18:159-169
Kondratova AA, Kondratova RV (2012) The circadian clock and pathology of the ageing brain. Nat Rev Neurosci 13:325-335

Lee S, Donehower LA, Herron AJ, Moore DD, Fu L (2010) Disrupting circadian homeostasis of sympathetic signaling promotes tumor development in mice. PLoS One 5(6). doi:10.1371/journal.pone.0010995

Leise TL, Harrington ME (2011) Wavelet-based time series analysis of circadian rhythms. J Biol Rhythm 26:454-463

Li H, Satinoff E (1998) Fetal tissue containing the suprachiasmatic nucleus restores multiple circadian rhythms in old rats. Am J Physiol 275:R1735-R1744

Marlatt MW, Potter MC, Lucassen PJ, van Praag H (2012) Running throughout middle-age improves memory function, hippocampal neurogenesis, and BDNF levels in female C57BL/6 J mice. Dev Neurobiol 72:943-952

Martino TA, Sole MJ (2009) Molecular time: an often overlooked dimension to cardiovascular disease. Circ Res 105:1047-1061

Martino TA, Oudit GY, Herzenberg AM, Tata N, Koletar MM, Kabir GM, Belsham DD, Backx PH, Ralph MR, Sole MJ (2008) Circadian rhythm disorganization produces profound cardiovascular and renal disease in hamsters. Am J Physiol Regul Integr Comp Physiol 294:R1675-R1683

Mrosovsky N, Biello SM (1994) Nonphotic phase shifting in the old and the cold. Chronbiol Int 11:232-252

Münch M, Knoblauch V, Blatter K, Schröder C, Schnitzler C, Kräuchi K, Wirz-Justice A, Cajochen C (2005) Age-related attenuation of the evening circadian arousal signal in humans. Neurobiol Aging 26:1307-1319

Nagano M, Adachi A, Nakahama K, Nakamura T, Tamada M, Meyer-Bernstein E, Sehgal A, Shigeyoshi Y (2003) An abrupt shift in the day/night cycle causes desynchrony in the mammalian circadian center. J Neurosci 23:6141-6151

Nakamura W, Yamazaki S, Takasu NN, Mishima K, Block GD (2005) Differential response of Period 1 expression within the suprachiasmatic nucleus. J Neurosci 25:5481-5487

Nakamura TJ, Nakamura W, Yamazaki S, Kudo T, Cutler T, Colwell CS, Block GD (2011) Age-related decline in circadian output. J Neurosci 31:10201-10205

Nebes RD, Buysse DJ, Halligan EM, Houck PR, Monk TH (2009) Self-reported sleep quality predicts poor cognitive performance in healthy older adults. J Gerontol B Psychol Sci Soc Sci 64:180-187

Palomba M, Nygård M, Florenzano F, Bertini G, Kristensson K, Bentivoglio M (2008) Decline of the presynaptic network, including GABAergic terminals, in the aging suprachiasmatic nucleus of the mouse. J Biol Rhythm 23:220-231

Passos GS, Poyares D, Santana MG, D'Aurea CV, Youngstedt SD, Tufik S, de Mello MT (2011) Effects of moderate aerobic exercise training on chronic primary insomnia. Sleep Med 12:1018-1027

Power A, Hughes AT, Samuels RE, Piggins HD (2010) Rhythmpromoting actions of exercise in mice with deficient neuropeptide signaling. J Biol Rhythm 25:235-246

Reid KJ, Baron KG, Lu B, Naylor E, Wolfe L, Zee PC (2010) Aerobic exercise improves self-reported sleep and quality of life in older adults with insomnia. Sleep Med 11:934-940

Rusak B, Zucker I (1979) Neural regulation of circadian rhythms. Physiol Rev 59:449-526

Satinoff E, Li H, Tcheng TK, Liu C, McArthur AJ, Medanic M, Gillette MU (1993) Do the suprachiasmatic nuclei oscillate 
in old rats as they do in young ones? Am J Physiol 265: R1216-R1222

Schaap J, Meijer JH (2001) Opposing effects of behavioural activity and light on neurons of the suprachiasmatic nucleus. Eur J Neurosci 13:1955-1962

Sellix MT, Evans JA, Leise TL, Castanon-Cervantes O, Hill D, DeLisser P, Block GD, Menaker M, and Davidson AJ (2012) Altered re-entrainment responses of the circadian timing system in old mice. J Neurosci 32:16193-16202

Swaab DF, Fliers E, Partiman TS (1985) The suprachiasmatic nucleus of the human brain in relation to sex, age and senile dementia. Brain Res 342:37-44

Tahara Y, Kuroda H, Saito K, Nakajima Y, Kubo Y, Ohnishi N, Seo Y, Otsuka M, Fuse Y, Ohura Y, Komatsu T, Moriya Y, Okada S, Furutani N, Hirao A, Horikawa K, Kudo T, Shibata S (2012) In vivo monitoring of peripheral circadian clocks in the mouse. Curr Biol 22:1029-1034

Tranah GJ, Blackwell T, Ancoli-Israel S, Paudel ML, Ensrud KE, Cauley JA, Redline S, Hillier TA, Cummings SR, Stone KL, Study of Osteoporotic Fractures Research Group (2010) Circadian activity rhythms and mortality: the study of osteoporotic fractures. J Am Geriatr Soc 58:282-291

Valentinuzzi VS, Scarbrough K, Takahashi JS, Turek FW (1997) Effects of aging on the circadian rhythm of wheelrunning activity in C57BL/6 mice. Am J Physiol 273: R1957-R1964

vanderLeest HT, Vansteensel MJ, Duindam H, Michel S, Meijer JH (2009) Phase of the electrical activity rhythm in the $\mathrm{SCN}$ in vitro not influenced by preparation time. Chronobiol Int 26:1075-1089

Watanabe A, Shibata S, Watanabe S (1995) Circadian rhythm of spontaneous neuronal activity in the suprachiasmatic nucleus of old hamster in vitro. Brain Res 695:237-239
Yamazaki S, Kerbeshian MC, Hocker CG, Block GD, Menaker M (1998) Rhythmic properties of the hamster suprachiasmatic nucleus in vivo. J Neurosci 18:10709-10723

Yamazaki S, Numano R, Abe M, Hida A, Takahashi R, Ueda M, Block GD, Sakaki Y, Menaker M, Tei H (2000) Resetting central and peripheral circadian oscillators in transgenic rats. Science 288:682-685

Yamazaki S, Straume M, Tei H, Sakaki Y, Menaker M, Block GD (2002) Effects of aging on central and peripheral mammalian clocks. Proc Natl Acad Sci U S A 99:1080110806

Yannielli PC, Harrington ME (2000) Neuropeptide Y applied in vitro can block the phase shifts induced by light in vivo. Neuroreport 11:1587-1591

Yoo SH, Yamazaki S, Lowrey PL, Shimomura K, Ko CH, Buhr ED, Siepka SM, Hong HK, Oh WJ, Yoo OJ, Menaker M, Takahashi JS (2004) PERIOD2::LUCIFERASE real-time reporting of circadian dynamics reveals persistent circadian oscillations in mouse peripheral tissues. Proc Natl Acad Sci U S A 101:5339-5346

Yoshikawa T, Yamazaki S, Menaker M (2005) Effects of preparation time on phase of cultured tissues reveal complexity of circadian organization. J Biol Rhythm 20:500-512

Zhang Y, Kornhauser JM, Zee PC, Mayo KE, Takahashi JS, Turek FW (1996) Effects of aging on light-induced phaseshifting of circadian behavioral rhythms, Fos expression and CREB phosphorylation in the hamster suprachiasmatic nucleus. Neuroscience 70:951-961

Zhang Y, Brainard GC, Zee PC, Pinto LH, Takahashi JS, Turek FW (1998) Effects of aging on lens transmittance and retinal input to the suprachiasmatic nucleus in golden hamsters. Neurosci Lett 258:167-170 